\title{
Endoscopic retrieval of a migrated pancreatic stent using a handmade catheter with a guidewire loop
}

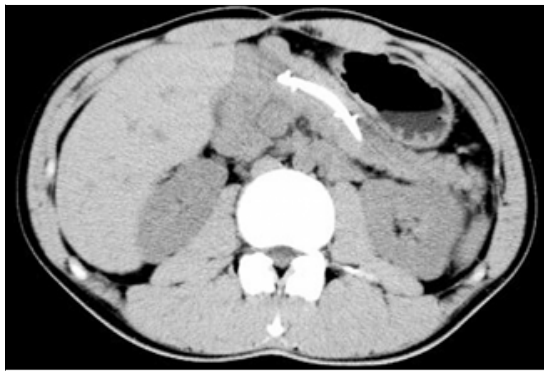

- Fig. 1 Computed tomography showing a pancreatic stent that has migrated into the pancreatic duct.

Endoscopic pancreatic stenting (EPS) is performed to relieve obstruction to pancreatic juice flow in patients with various pancreatic conditions [1]. Migration of plastic pancreatic stents is one complication of EPS and occurs at a rate of $5 \%-6 \%$ [2]. The migrated stent should be removed because it may induce a severe pancreatic condition [3]. However, endoscopic removal is technically difficult owing to the small diameter, bending course, and strictures of the pancreatic duct $[3,4]$. We describe an innovative technique for removing a migrated pancreatic stent.

A 16-year-old male patient who underwent pancreaticoduodenectomy for treatment of traumatic pancreatic injury presented with mild pancreatitis due to pancreaticojejunal anastomotic stenosis. EPS was successfully performed under double-balloon endoscopic retrograde cholangiopancreatography. Four months later, computed tomography revealed proximal migration of the pancreatic stent ( $\triangleright$ Fig. 1). Conventional approaches for retrieval using a basket catheter and snare failed.

A handmade catheter with a guidewire loop was created using a double-lumen catheter (uneven double-lumen catheter; Piolax Medical Devices, Kanagawa, Japan) and a 0.025 inch guidewire (Radifocus; Terumo, Tokyo, Japan) ( $\triangleright$ Fig. 2) as follows. First, the catheter was cut to
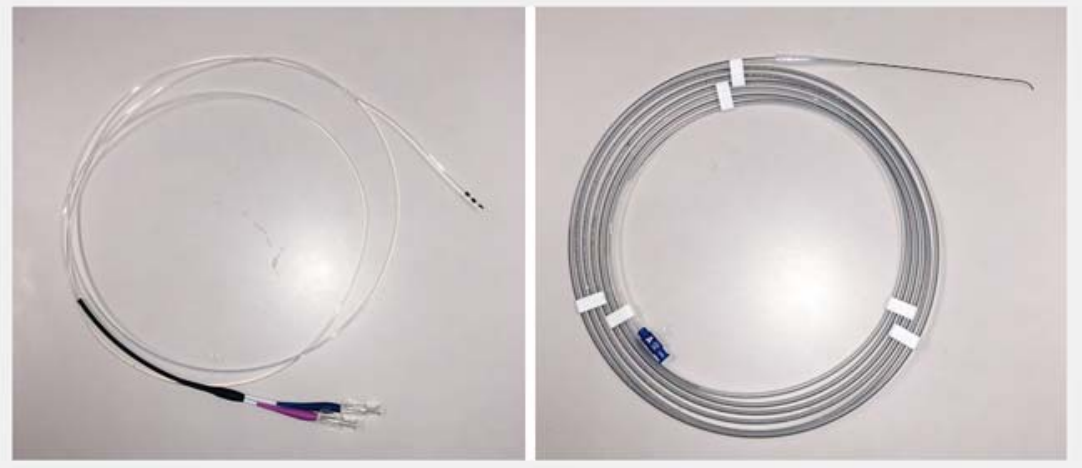

- Fig. 2 Double-lumen catheter (uneven double-lumen catheter; Piolax, Kanagawa, Japan) and 0.025 inch guidewire (Radifocus guidewire; Terumo, Tokyo, Japan).
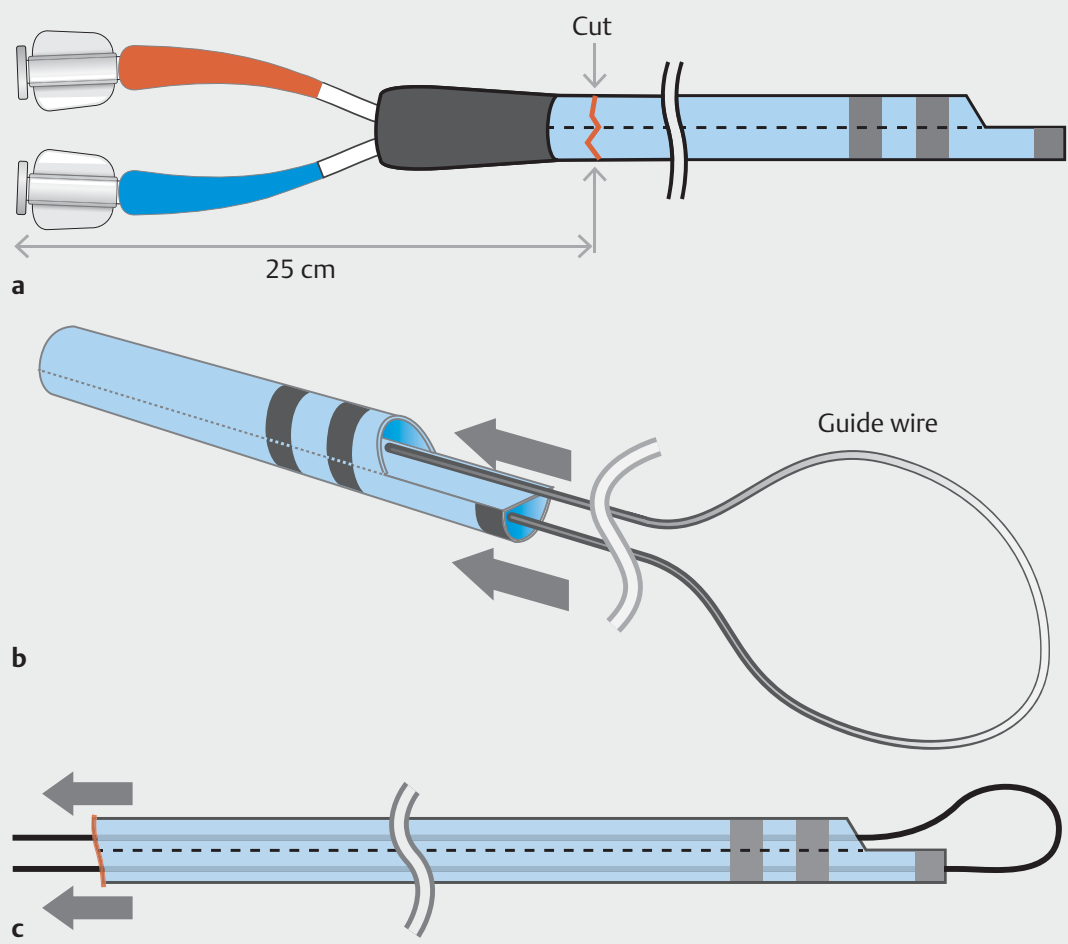

Fig. 3 Schema showing a handmade catheter with guidewire loop. Cutting of the catheter to a $25 \mathrm{~cm}$ length from the edge of the injection side. Insertion of the wire into both open ends of the double-lumen catheter. Completion of the guidewire loop. 

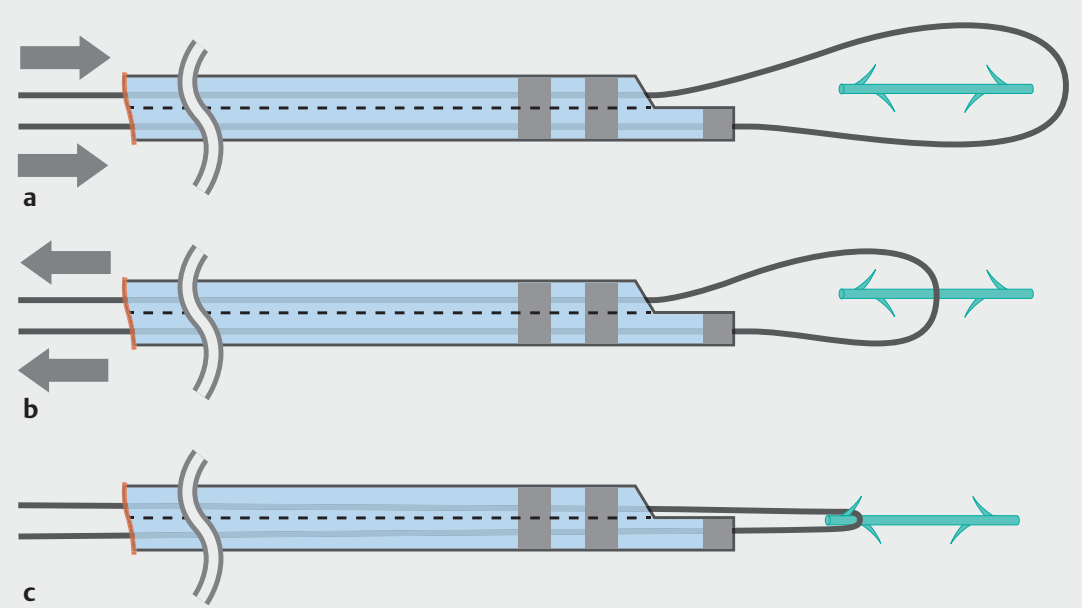

C

Fig.4 Schema showing the removal procedure. Opening of the guidewire loop over the distal aspect of the stent. Size adjustment of the loop. Capture of the stent flap.

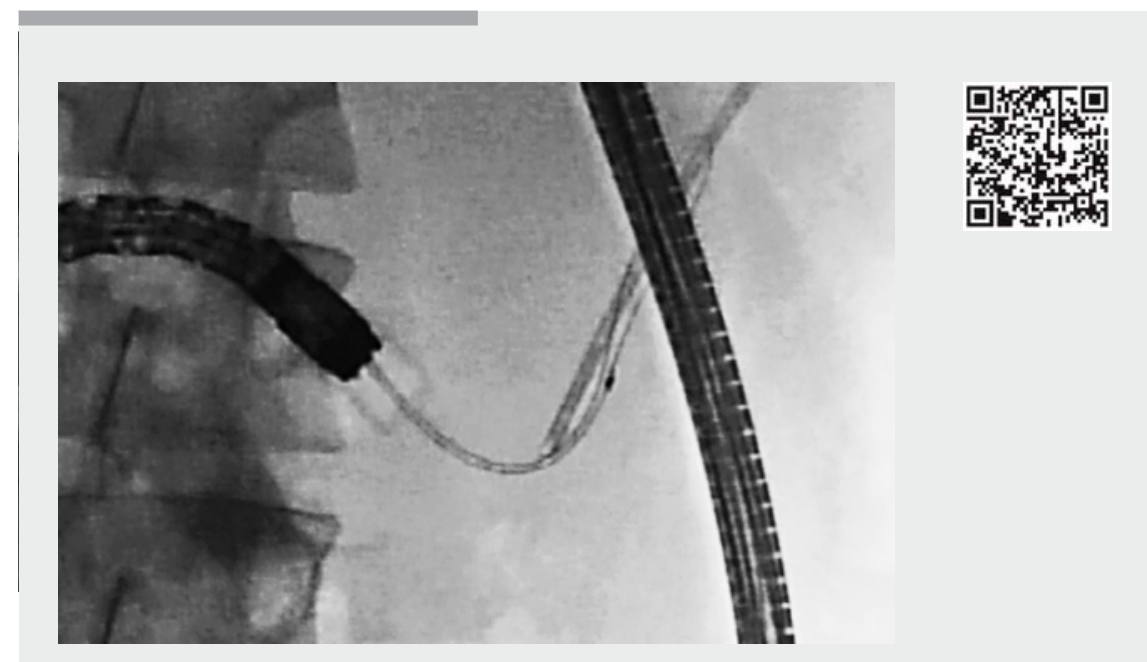

Video 1 An innovative procedure for retrieval of a migrated pancreatic stent using a handmade catheter with a guidewire loop. a $25 \mathrm{~cm}$ length from the edge of the tail side to facilitate guidewire maneuver. Next, both tips of the guidewire were inserted into the open ends of the doublelumen catheter ( $>$ Fig. 3 ). The following procedure ( $\triangleright$ Fig. 4 ) was then performed after obtaining written informed consent. The catheter with the guidewire loop was cannulated over the distal aspect of the stent. The size of the loop was adjusted by simultaneously pushing both guidewires, and the proximal flap of the stent was captured by minimizing the size of the guidewire loop ( $\triangleright$ Fig.5). Finally, the migrated pancreatic stent

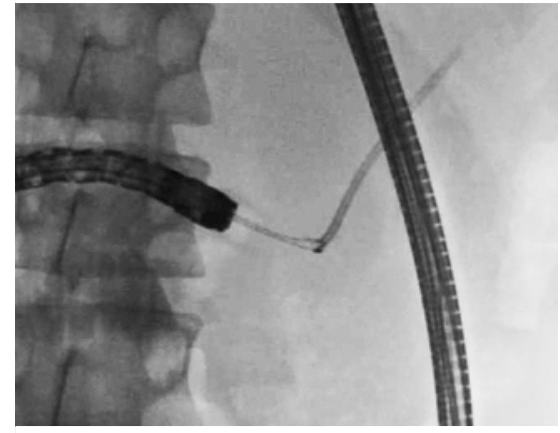

- Fig. 5 Fluoroscopic image showing removal of the proximal stent captured by minimizing the size of the guidewire loop.

Competing interests

None

The authors

Hideki Kamada', Hideki Kobara', Kiyoyuki Kobayashi' ${ }^{1}$, Keiichi Okano ${ }^{2}$, Yasuyuki Suzuki², Kiyohito Kato ${ }^{1}$, Tsutomu Masaki ${ }^{1}$

1 Department of Gastroenterology and Neurology, Faculty of Medicine, Kagawa University, Kagawa, Japan

2 Department of Gastroenterological Surgery, Faculty of Medicine, Kagawa University, Kagawa, Japan

\section{Corresponding author}

\section{Hideki Kamada, MD}

Department of Gastroenterology and Neurology, Faculty of Medicine, Kagawa University, 1750-1 Ikenobe, Kagawa 7610793, Japan

Fax: +81-87-8912158

kamacho@med.kagawa-u.ac.jp

was successfully retrieved without grasp slippage or complications ( $\triangleright$ Video 1 ).

This novel procedure can be a simple, safe, and effective option for removing a migrated pancreatic stent.

Endoscopy_UCTN_Code_TTT_1AR_2AZ

\section{Acknowledgments}

We thank Angela Morben, DVM, ELS, from Edanz Group (www.edanzediting.com/ac) for editing a draft of this manuscript.

\section{References}

[1] Liao YS, Zhao Q, Fan Y et al. Proximal migration of a 5 French pancreatic stent during bile stone extraction: a successful retrieval using mini-snare. Niger J Clin Pract 2014; 17: 384-386

[2] Rahimi AR, Ejtehadi F. SpyGlass pancreatoscopy and successful retrieval of a proximally migrated pancreatic stent; unusual case and technical tips. Middle East J Dig Dis 2016; 8: 232-234 
[3] Matsumoto K, Katanuma A, Maguchi H. Endoscopic removal technique of migrated pancreatic plastic stents. J Hepatobiliary Pancreat Sci 2014; 21: E34-E40

[4] Lu Y, Jin Z, Wu JC et al. Endoscopic retrieval technique of proximally migrated pancreatic stents: a retrospective study in a tertiary centre. Gastroenterol Res Pract 2015; 2015: 485980

\section{Bibliography}

DOI https://doi.org/10.1055/a-0751-2569

Published online: 7.11.2018

Endoscopy 2019; 51: E7-E9

(c) Georg Thieme Verlag KG

Stuttgart · New York

ISSN 0013-726X

\section{ENDOSCOPY E-VIDEOS}

https://eref.thieme.de/e-videos

口回 Endoscopy E-Videos is a free access online section, reporting 回: on interesting cases and new

techniques in gastroenterological endoscopy. All papers include a high quality video and all contributions are freely accessible online.

This section has its own submission website at

https://mc.manuscriptcentral.com/e-videos 